Article

\title{
Sunlight-Active BiOI Photocatalyst as an Efficient Adsorbent for the Removal of Organic Dyes and Antibiotics from Aqueous Solutions
}

\author{
Teerapong Narenuch, Teeradech Senasu, Tammanoon Chankhanittha and Suwat Nanan *D
}

Citation: Narenuch, T.; Senasu, T.; Chankhanittha, T.; Nanan, S. Sunlight-Active BiOI Photocatalyst as an Efficient Adsorbent for the Removal of Organic Dyes and Antibiotics from Aqueous Solutions. Molecules 2021, 26, 5624. https:// doi.org/10.3390/molecules26185624

Academic Editor: Marcello Brigante

Received: 25 August 2021

Accepted: 14 September 2021

Published: 16 September 2021

Publisher's Note: MDPI stays neutral with regard to jurisdictional claims in published maps and institutional affiliations.

Copyright: (C) 2021 by the authors Licensee MDPI, Basel, Switzerland. This article is an open access article distributed under the terms and conditions of the Creative Commons Attribution (CC BY) license (https:// creativecommons.org/licenses/by/ $4.0 /)$.
Materials Chemistry Research Center, Center of Excellence for Innovation in Chemistry (PERCH-CIC), Department of Chemistry, Faculty of Science, Khon Kaen University, Khon Kaen 40002, Thailand; teerapong_narenuch@kkumail.com (T.N.); teera_sen@kkumail.com (T.S.); tammanoon_chan@hotmail.com (T.C.) * Correspondence: suwatna@kku.ac.th; Tel.: +66-43-202222-41 (ext. 12370); Fax: +66-43-202373

\begin{abstract}
A bismuth oxyiodide (BiOI) photocatalyst with excellent sunlight-driven performance was synthesized by a solvothermal route without the addition of surfactants or capping agents. The prepared photocatalyst exhibited a tetragonal phase with an energy band gap of $2.15 \mathrm{eV}$. The efficiency of the photocatalyst was elucidated by monitoring the photodegradation of organic dyes and antibiotics. The BiOI photocatalyst provided a 95\% removal of norfloxacin (NOR) antibiotics under visible light illumination. Interestingly, the complete removal of Rhodamine B (RhB) dye was achieved after $80 \mathrm{~min}$ of natural sunlight irradiation. The photodegradation reaction followed the first-order reaction. Both photo-generated holes and electrons play vital roles in the photodegradation of the pollutant. The BiOI photocatalyst remains stable and still shows a high efficiency even after the fifth run. This confirms the great cycling ability and high structural stability of the photocatalyst. The prepared BiOI catalyst, with a high surface area of $118 \mathrm{~m}^{2} \mathrm{~g}^{-1}$, can act as an excellent adsorbent as well. The synergistic effect based on both adsorption and photocatalysis is a key factor in achieving a very high removal efficiency. The photoactivity under sunlight is higher than that observed under visible light, supporting the practical use of the BiOI photocatalyst for the removal of organic pollutants in wastewater through the utilization of abundant solar energy.
\end{abstract}

Keywords: BiOI; photodegradation; antibiotics; organic dyes; solar light

\section{Highlights:}

- A BiOI photocatalyst was successfully prepared using a solvothermal method.

- The complete photodegradation of RhB dye under solar light irradiation was achieved.

- The photodegradation reaction correlated well with the first-order kinetics model.

- $\quad$ The BiOI photocatalyst exhibited good structural stability and reusability after five cycles.

\section{Introduction}

It has been reported that considerable attention has been paid to contamination by organic pollutants in natural water [1]. The promotion of antibiotic-resistant bacteria and threats to ecosystem stability are two major problems. Fluoroquinolone-based antibiotics have been utilized for the treatment of bacterial-infectious diseases [2]. In addition, upon industrial development, a massive number of organic dyes have been discharged into natural water [3]. Some dyes have been shown to have carcinogenic and mutagenic properties. It has been reported that the large-scale usage of both organic dyes and antibiotic drugs causes a serious threat to the environment [2-4]. Thus, the removal of these pollutants from the ecosystem is urgently needed [5].

The removal of organic pollutants by some conventional treatments has been reported. The incomplete degradation of the pollutants together with the creation of secondary hazardous pollutants are the main drawbacks of this method [2]. Interestingly, photocatalytic 
treatment is a clean and eco-friendly process for the degradation of pollutants [5-9]. It is generally known that commercially available $\mathrm{TiO}_{2}$ is a UV-active photocatalyst (band gap of $3.2 \mathrm{eV}$ ). Thus, $\mathrm{TiO}_{2}$ shows a low performance under natural sunlight $[10,11]$. Interestingly, the development of visible-light-active photocatalysts is a challenging and promising research topic in the field of environmental protection. The removal of organic pollutants in wastewater can be performed very easily by the utilization of economical sunlight [12-15].

The synthesis of numerous Bi-based photocatalysts, showing an Aurivillius structure, including $\mathrm{Bi}_{2} \mathrm{MoO}_{6}, \mathrm{BiVO}_{4}$, and $\mathrm{BiOX}(\mathrm{X}=\mathrm{Cl}$, I, and $\mathrm{Br})$, has been investigated [16-24]. $\mathrm{BiOI}\left(E_{\mathrm{g}}\right.$ of $\left.1.5-1.7 \mathrm{eV}\right)$, which shows a high photocatalytic performance, has received great attention. This is due to its advantages of non-toxicity, great stability, and high sunlightactive photocatalytic performance [25]. The synthesis of BiOI by various techniques has been reported [26,27]. Practically, the solvothermal/hydrothermal route has been used for the preparation of many nanomaterials because of its advantages of simplicity and low expense. In addition, the fabrication of samples on a large scale can be performed using the solvothermal process [24].

This research focuses on the solvothermal fabrication of BiOI. The performance of the prepared photocatalyst was monitored by examining the photodegradation of organic dyes and antibiotics. The efficiency reached $71 \%$ and $95 \%$ rates of degradation of RhB dye and NOR antibiotics under visible light irradiation. The BiOI photocatalyst also exhibited the complete degradation of $\mathrm{RhB}$ dye under natural sunlight illumination, indicating its promising environmental protection properties for the detoxification of organic dyes and fluoroquinolone antibiotics in wastewater.

\section{Experiment}

2.1. Chemicals

The chemicals were utilized as received. The water was purified by a Millipore process $\left(18.2 \mathrm{M} \Omega \mathrm{cm}^{-1}\right)$.

\subsection{Fabrication of $\mathrm{BiOI}$}

The BiOI sample was fabricated using a solvothermal technique. Firstly, about $1.0878 \mathrm{~g}$ of $\mathrm{Bi}\left(\mathrm{NO}_{3}\right)_{3} \cdot 5 \mathrm{H}_{2} \mathrm{O}$ was dissolved in $30 \mathrm{~mL}$ of ethylene glycol. Secondly, about $0.3883 \mathrm{~g}$ of $\mathrm{KI}$ was dissolved in $30 \mathrm{~mL}$ of ethylene glycol. Thirdly, the KI solution was added to the bismuth nitrate solution. The mixed solution was then put into an autoclave at $160{ }^{\circ} \mathrm{C}$ for $12 \mathrm{~h}$. The precipitate was filtered, washed, and then dried at $80^{\circ} \mathrm{C}$ for $4 \mathrm{~h}$.

\subsection{Characterization}

The characterization of this substance has been reported elsewhere [3,6-9]. The crystal structure of the sample was investigated using powder X-ray diffraction (XRD) and monochromatic $\mathrm{Cu} \mathrm{K}$ radiation. The morphological structure of the sample was elucidated by the scanning electron microscopic (SEM) method. The vibrational spectrum was recorded using an FT-IR spectrophotometer. The KBr pellet method was used for sample preparation. The UV-vis diffused reflectance spectrum was examined. The photoluminescence (PL) spectrum was determined using an excitation wavelength of $360 \mathrm{~nm}$.

\subsection{Photocatalytic Degradation of the Pollutants}

The photocatalytic performance of the prepared BiOI catalyst was examined by determining the degradation of dyes and antibiotics under artificial visible light irradiation (a Panasonic daylight lamp, $15 \mathrm{~W}$ ) and natural solar light illumination. Both Rhodamine B $(\mathrm{RhB})$ and Rhodamine 6G (R6G) were used as models of organic dyes. In addition, both ofloxacin (OFL) and norfloxacin (NOR) were selected as representatives of fluoroquinolonebased antibiotics. The photocatalytic study can be seen in detail elsewhere [22,24]. The control experiment was performed by illuminating the pollutant solution without the addition of the prepared BiOI photocatalyst. The photocatalyst $(50 \mathrm{mg}$ ) was suspended in a pollutant solution of $10 \mathrm{mg} \mathrm{L}^{-1}$ (total volume of $200 \mathrm{~mL}$ ). About $5 \mathrm{~mL}$ of the sample 
was collected. The exact concentration of the pollutant was elucidated by measuring the absorbance at $\lambda_{\max }$ of 273, 286, 554, and $527 \mathrm{~nm}$, respectively, for NOR, OFL, RhB, and R6G, using a UV-vis spectrophotometer.

The performance of the photocatalyst in the photodegradation of the pollutant was determined by Equation (1):

$$
\text { Performance }(\%)=\left(1-\mathrm{C} / \mathrm{C}_{0}\right) \times 100 \%
$$

where $\mathrm{C}_{0}$ and $\mathrm{C}$ represent the initial concentration and the concentration of the pollutant solution after photo illumination.

The photoactivity of the BiOI photocatalyst can also be determined by calculating the photodegradation rate as follows:

$$
\begin{aligned}
& \mathrm{dC} / \mathrm{dt}=-\mathrm{k}_{\mathrm{app}} \mathrm{C} \\
& \ln \left(\mathrm{C}_{0} / \mathrm{C}\right)=\mathrm{k}_{\mathrm{app}} \mathrm{t}
\end{aligned}
$$

where $\mathrm{k}_{\mathrm{app}}$ represents the apparent rate constant of the first-order degradation reaction.

A trapping experiment was performed to study the active species involved in the degradation of RhB dye. The addition of $t$-butanol, $\mathrm{NaN}_{3}$, EDTA-2Na, and $\mathrm{K}_{2} \mathrm{Cr}_{2} \mathrm{O}_{7}$ to quench the hydroxyl radical, superoxide anion radical, hole, and electron, respectively, was carried out. Each scavenger $(5 \mathrm{mM})$ was incorporated before the addition of the photocatalyst $(50 \mathrm{mg})$. All other conditions were similar to those of the no-scavenger process.

The hydroxyl radicals were also monitored by the incorporation of the photocatalyst (50 mg) in a terephthalic acid (TA) solution $(50 \mathrm{~mL})$. The sample was then examined by a spectrofluorometric method using an excitation wavelength $\left(\lambda_{\text {excitation }}\right)$ of $315 \mathrm{~nm}$.

The cycling ability of the prepared BiOI photocatalyst was also checked. After the first cycle of the photodegradation study, the photocatalyst was filtered, washed with ethanol and water, and dried at $80^{\circ} \mathrm{C}$ for $6 \mathrm{~h}$. The photocatalyst was then used for five successive cycles.

\section{Results and Discussion}

\subsection{Characterization of the BiOI Photocatalyst}

The XRD pattern of the prepared BiOI photocatalyst (Figure 1a) exhibited the peaks of a tetragonal structure at a $2 \theta$ of $28.96^{\circ}, 31.73^{\circ}, 45.43^{\circ}$, and $54.91^{\circ}$, corresponding to the reflection from the (102), (110), (200), and (212) lattice planes, respectively (JCPDS card no. 73-2060) [25]. No impurity peaks were observed. The crystallite size of the sample was determined from the width of the most intense peak $\left(2 \theta=31.73^{\circ}\right)$ following the Scherrer equation. The BiOI photocatalyst showed the crystallite size of about $14.90 \mathrm{~nm}$.

The vibrational spectrum of the BiOI (Figure $1 \mathrm{~b}$ ) provided vibrational bands at $519 \mathrm{~cm}^{-1}$ and $1311 \mathrm{~cm}^{-1}$ which were attributed to the Bi-O stretching mode and stretching vibrational mode of Bi-I bond, respectively [25]. The peak found at $1627 \mathrm{~cm}^{-1}$ was due to the flexural vibration of $\mathrm{O}-\mathrm{H}$ in the adsorbed water [25]. In addition, the vibration band at $3465 \mathrm{~cm}^{-1}$ was assigned to the stretching vibration of water as well.

The UV-vis diffuse reflectance spectrum in Figure 1c provided the band gap energy $\left(E_{\mathrm{g}}\right)$ of $2.15 \mathrm{eV}$ following the Kubelka-Munk equation [22]. The sample provided promising visible-light-active photoactivity with an absorption edge of $577 \mathrm{~nm}$. The charge carrier separation efficiency at the interface of the sample was determined from the photoluminescence spectrum (Figure 1d). The photocatalyst showed a PL peak at $469 \mathrm{~nm}$ with a high crystallinity [24]. 


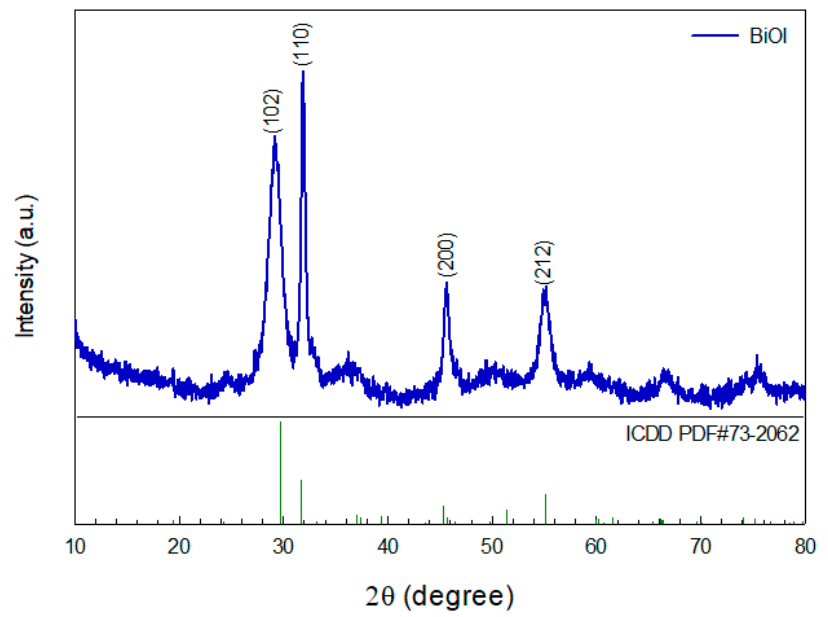

(a)

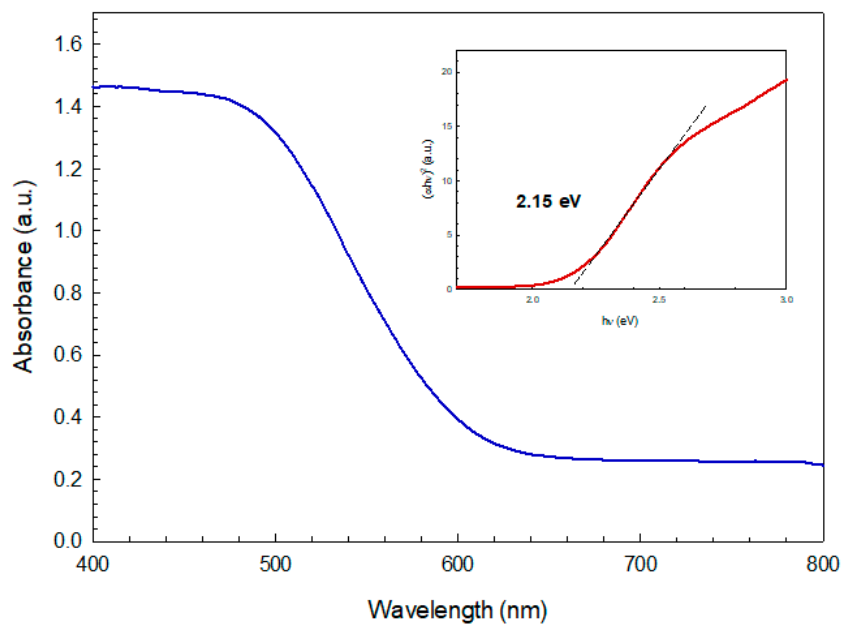

(c)

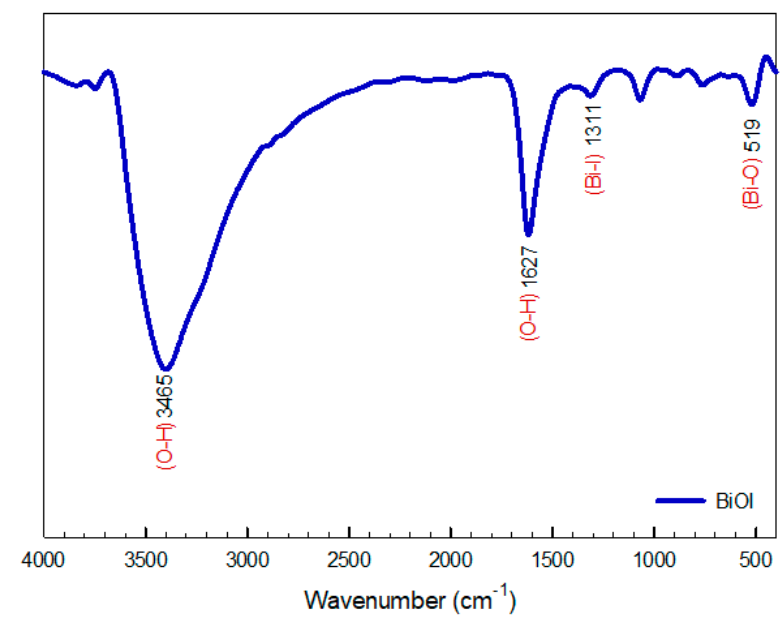

(b)

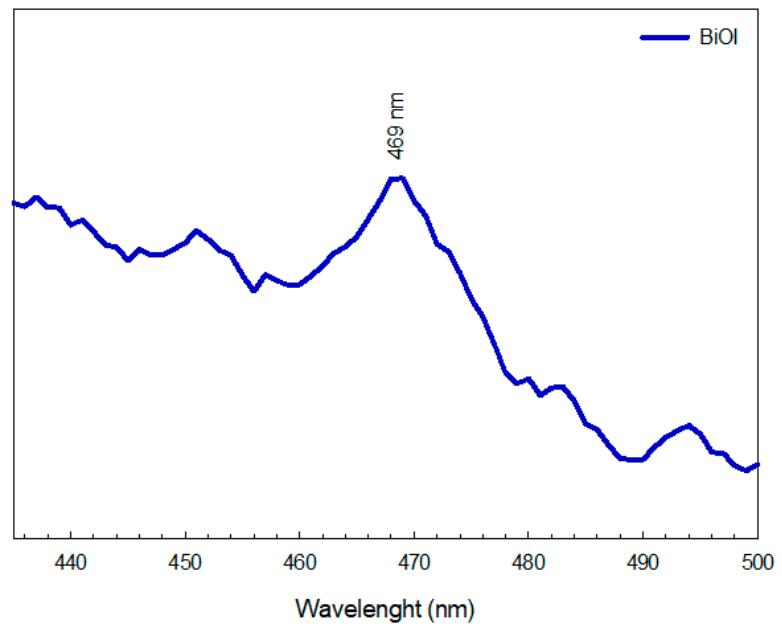

(d)

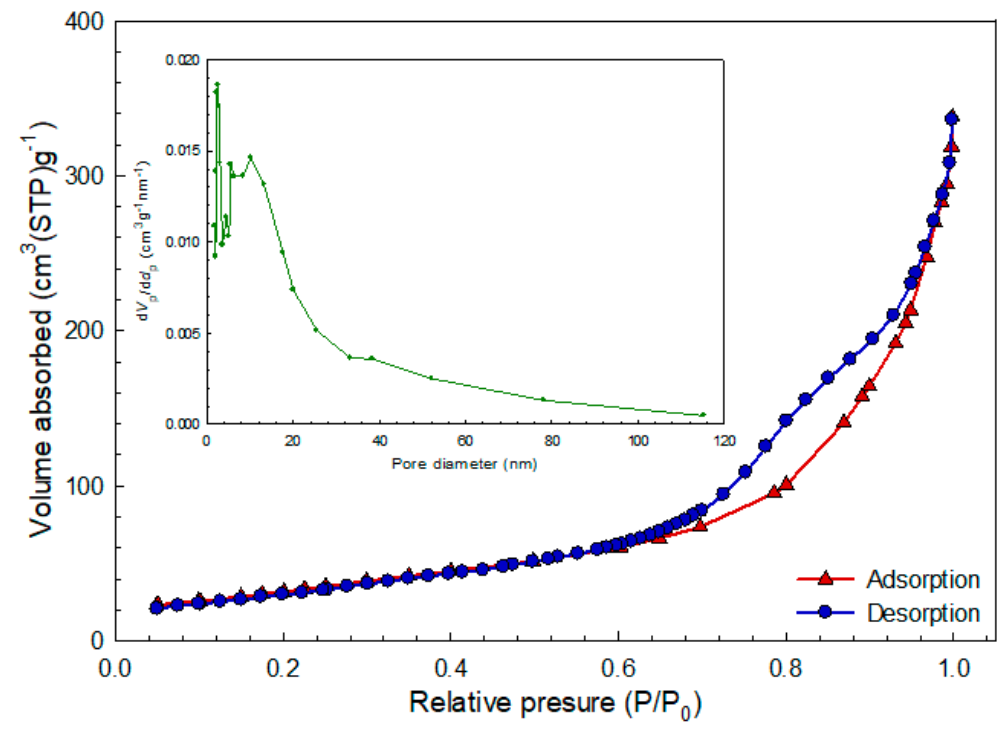

(e)

Figure 1. XRD pattern (a), FT-IR spectrum (b), UV-vis spectrum (c), PL spectrum (d), and nitrogen adsorption-desorption isotherm and $\mathrm{BJH}$ pore size distribution of the $\mathrm{BiOI}$ photocatalyst (e).

In principle, it is well-accepted that the surface area and pore size of the sample strongly affects the adsorption ability and the photocatalytic performance of the resultant 
photocatalyst. Thus, the $\mathrm{N}_{2}$ adsorption-desorption isotherm was determined and then the BET surface area was elucidated. In addition, the BJH pore-size distribution of the sample was also investigated. The synthesized BiOI photocatalyst provided a high specific surface area of $118.19 \mathrm{~m}^{2} \mathrm{~g}^{-1}$, as shown in Figure 1e. The sample showed the type-IV isotherm, following the IUPAC classification, with the hysteresis loop of $\mathrm{H}_{3}$ indicating the existence of the mesopores in the prepared photocatalyst. The total pore volume of $0.45 \mathrm{~cm}^{2} \mathrm{~g}^{-1}$ and a pore size of $15.24 \mathrm{~nm}$ were reported. All in all, the very high surface area and meso-porous structure of the prepared $\mathrm{BiOI}$ photocatalyst are beneficial for the enhancement of adsorption ability, which in turn results in an increase in pollutant removal efficiency [3,28].

The FE-SEM images of BiOI in Figure 2a,b show the spherical micro-structure of $3.41 \mu \mathrm{m}$, which has a flower-like morphology. It can be seen that each sphere was constructed using nanosheets as building blocks. The formation of the flower-like morphological structures is based on the connection of these nanosheets. The BiOI architectures were generated from the nanosheet arrays from the center to the surface of the spheres. In addition, it is well-accepted that BiOI shows a unique layered structure composed of $\left[\mathrm{Bi}_{2} \mathrm{O}_{2}\right]^{2+}$ slabs interleaved by double slabs of iodine atoms [15]. It should be noted that ethylene glycol (EG), as a solvent, also plays an important role in controlling the final morphology of the sample. EG can act as a coordinating agent in the synthesis step, meaning that hierarchical BiOI structures can be achieved by inducing the self-assembly of the nanosheets to form hierarchical BiOI microspheres. The FESEM-EDX elemental mapping and EDX methods were used for investigating the elemental surface compositions and the distribution of the elements in the photocatalyst, respectively. The mapping micrographs (Figure $2 \mathrm{~d}$ ) confirmed the uniform dispersion of bismuth $(\mathrm{Bi})$, oxygen $(\mathrm{O})$, and iodine $(\mathrm{I})$ in the prepared photocatalyst. Additionally, the weight $\%$ and atomic $\%$ ratios of the O:Bi:I elements were 61.6:24.9:13.5 and 63.2:22.1:14.7, respectively (Figure 2c).

\subsection{Photodegradation Study}

The photoactivity of the prepared BiOI photocatalyst in the photodegradation of dyes and antibiotics under visible light and natural solar light irradiation was investigated.

\subsubsection{Photodegradation of Pollutants}

On examining the photodegradation of each pollutant under visible light illumination, a decrease in pollutant concentration with time was observed (Figure 3a). No photolysis of the pollutant was detected. In the present study, the performance of the BiOI with regard to the adsorption (in dark conditions) and photocatalytic degradation (under photo illumination) of the dyes and antibiotics was examined. The removal of these pollutants via the adsorption process was in the range of $41 \%(\mathrm{Rh} 6 \mathrm{G})$ to about $76 \%(\mathrm{RhB})$ after $240 \mathrm{~min}$. In the presence of the $\mathrm{BiOI}$ photocatalyst and light, the lowering of the pollutant concentration $\left(C / C_{0}\right)$ with time was continuously observed after $240 \mathrm{~min}$. The enhanced photoactivity reached $71 \%$ and $95 \%$ in the degradation of the NOR antibiotic and RhB dye, respectively (Figure $3 b$ ). The photodegradation reaction fit very well with the first-order reaction [3]. In addition, solar light-responsive photocatalytic performances of $80 \%$ and $99 \%$ were detected in the degradation of NOR and RhB, respectively (Figure 4). A removal of the pollutant via the adsorption process in the rage of $60 \%$ (NOR) to $76 \%$ (RhB) was reported. This may be due to the very high surface area (about $118 \mathrm{~m}^{2} \mathrm{~g}^{-1}$ ) of the prepared BiOI, which can act as an excellent adsorbent as well. The synergistic effect based on both adsorption and photocatalysis is a key factor concerning a very high pollutant removal efficiency. The photoactivity under sunlight is higher than that observed under visible light, supporting the practical use of the $\mathrm{BiOI}$ photocatalyst for the removal of toxic pollutants by utilizing abundant solar energy [8]. 


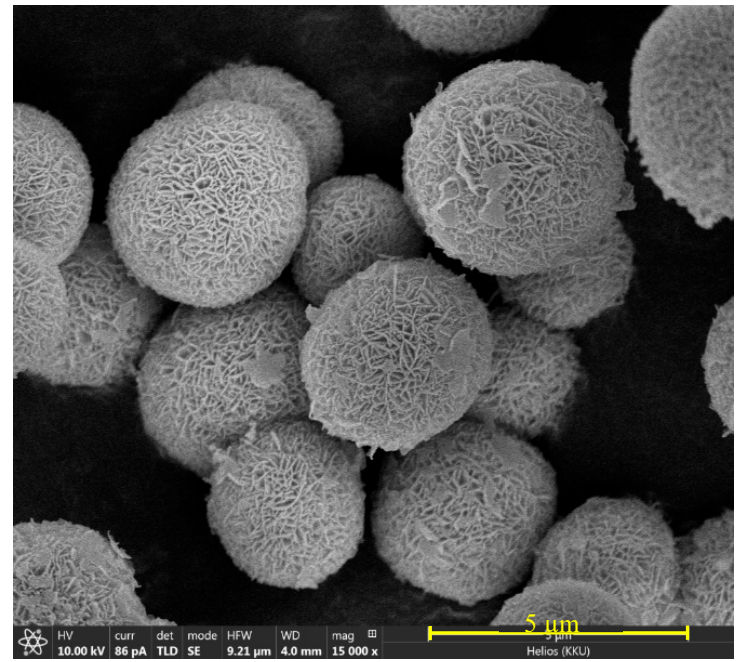

(a)

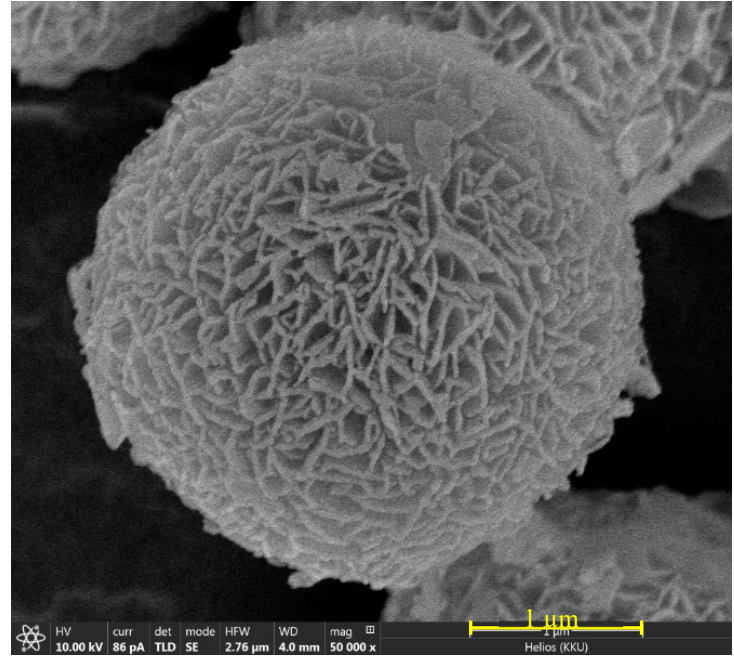

(b)

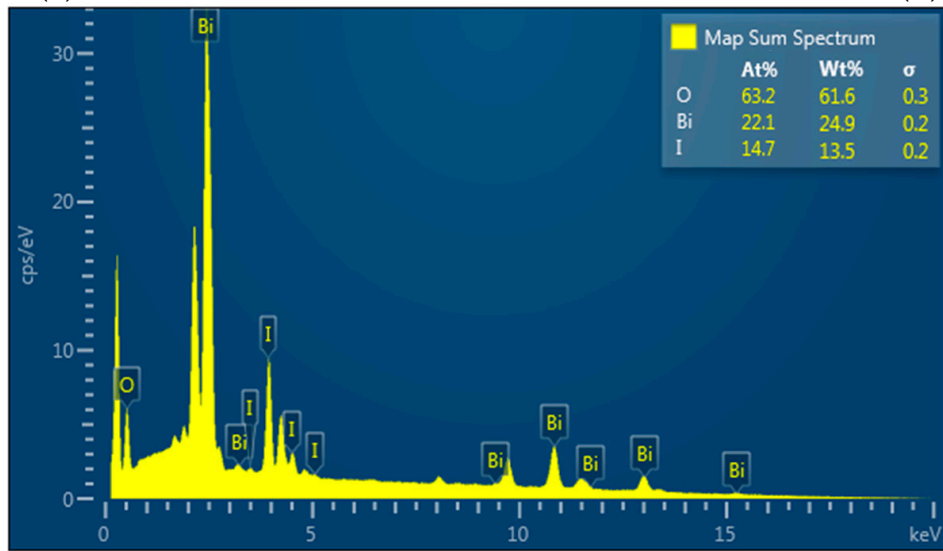

(c)

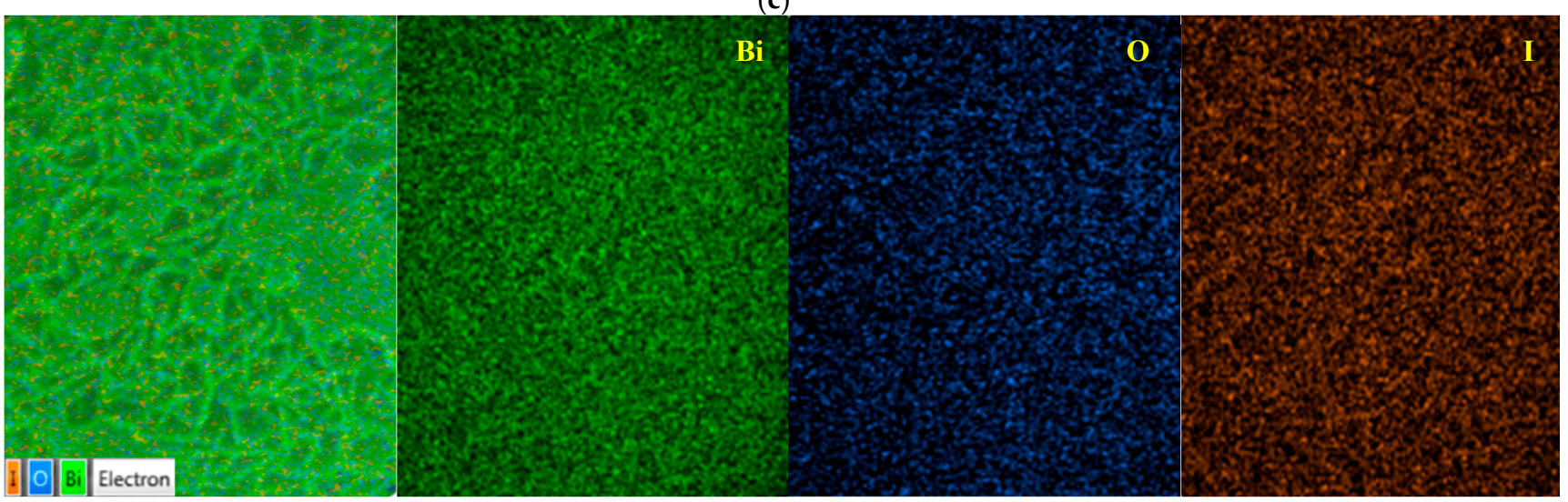

(d)

Figure 2. SEM micrographs (a,b); EDX spectrum (c); SEM micrograph of the mapping area; and EDX elementary mapping of $\mathrm{Bi}, \mathrm{O}$, and I obtained from the prepared $\mathrm{BiOI}$ photocatalyst $(\mathbf{d})$. 


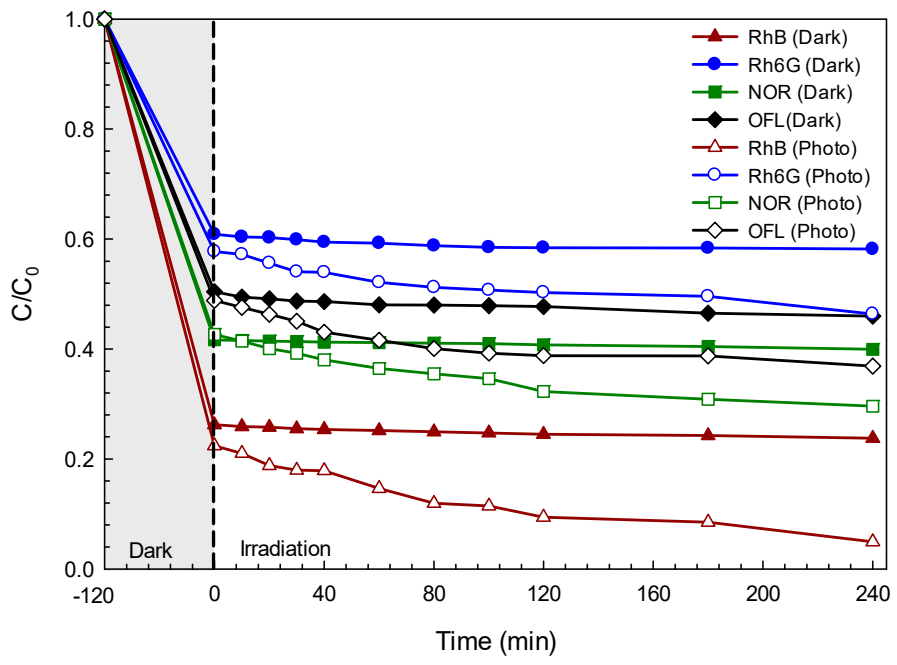

(a)

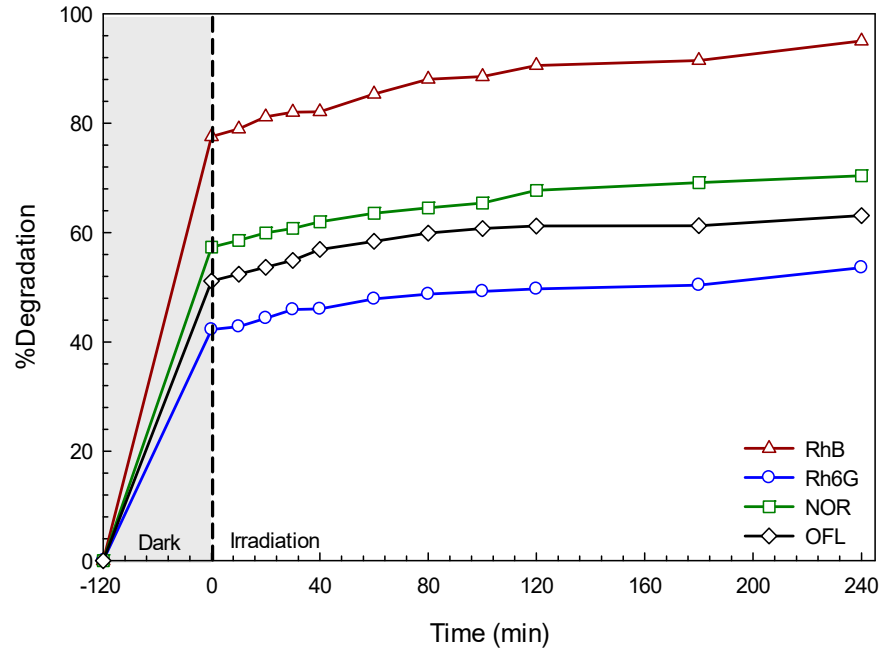

(b)

Figure 3. Plots of pollutant concentration $\left(C / C_{0}\right)$ vs. time in the presence of BiOI photocatalyst under visible light irradiation (a) and the corresponding photocatalytic efficiency (b).

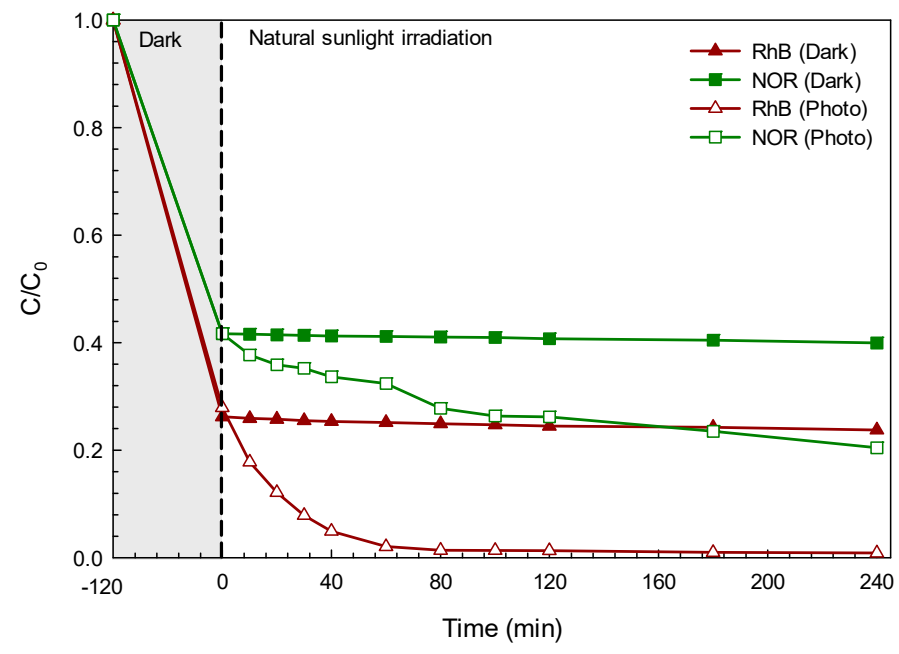

(a)

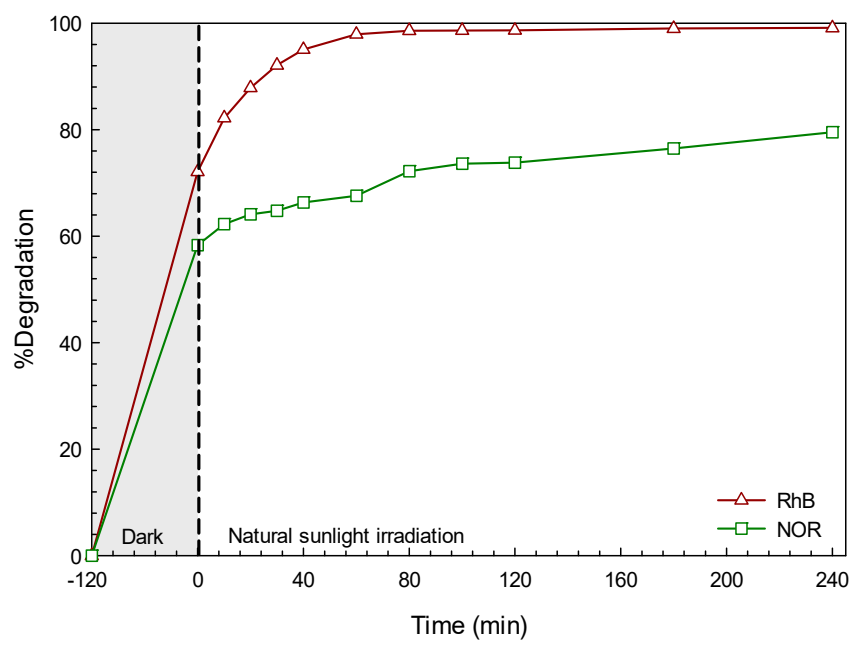

(b)

Figure 4. Plots of pollutant concentration $\left(\mathrm{C} / \mathrm{C}_{0}\right)$ vs. time in the presence of BiOI photocatalyst under natural sunlight irradiation (a) and the corresponding photocatalytic efficiency (b).

To confirm the mineralization of the pollutant solution, the total organic carbon (TOC) was investigated in the photodegradation of RhB dye. A decrease in the TOC content with an increase in the photo illumination time was detected (Figure 5a), implying the mineralization of the RhB dye by the BiOI photocatalyst under photo illumination. A performance of $70 \%$ was observed after $240 \mathrm{~min}$ of light irradiation (Figure $5 \mathrm{~b}$ ). The TOC result confirmed the oxidation of the $\mathrm{RhB}$ dye to $\mathrm{CO}_{2}, \mathrm{H}_{2} \mathrm{O}$, and some small molecules. The result agrees well with those reported previously in the literature regarding the photodegradation of organic dyes in the presence of either $\mathrm{ZnO}$ or $\mathrm{BiOCl}$ photocatalysts [8,24]. 


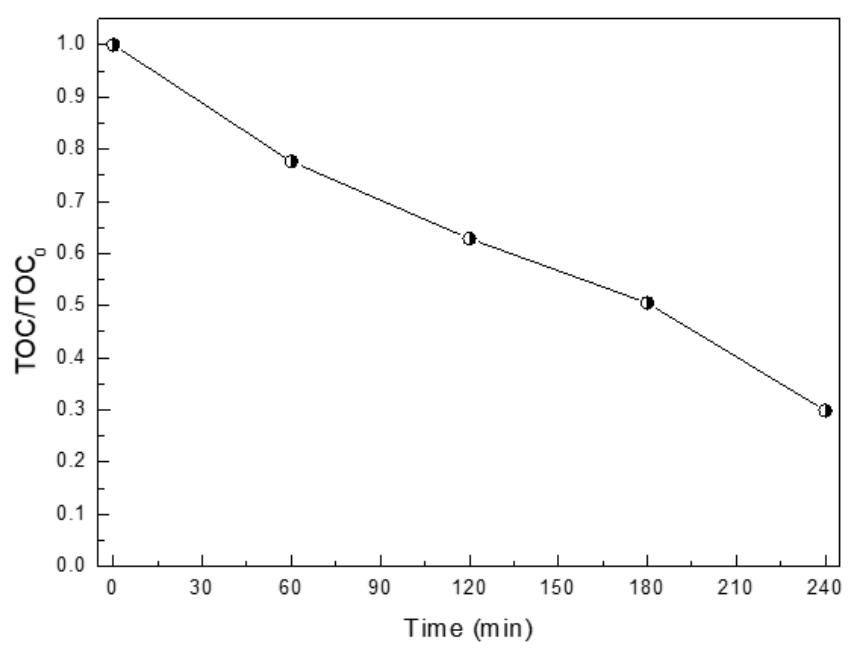

(a)

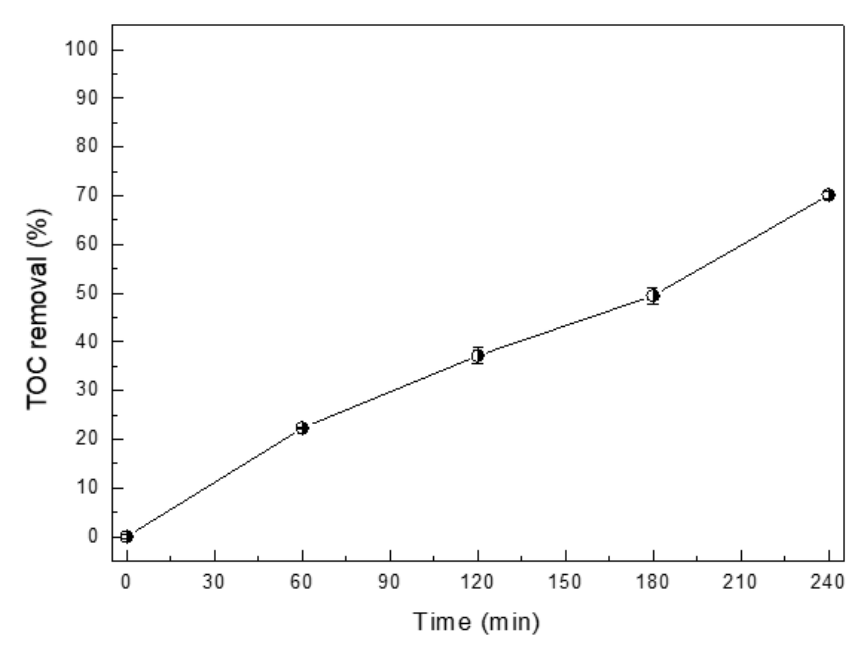

(b)

Figure 5. Total organic carbon (TOC) in RhB dye solution as a function of time (a) and the corresponding photocatalytic activity (b).

The effect of some parameters including the initial concentration, photocatalyst content, and initial solution $\mathrm{pH}$ on the photodegradation of Rhodamine B (RhB dye) was elucidated [3]. In principle, $\mathrm{pH}$ is one important factor affecting photocatalytic performance. It has been reported that changes in $\mathrm{pH}$ remarkably affected the photodegradation rate of an organic pollutant $[8,24,28]$. Thus, the influence of the solution $\mathrm{pH}$ on the degradation of $\mathrm{RhB}$ dye was investigated. A pH of about 7 is the natural $\mathrm{pH}$ of $\mathrm{RhB}$ dye solution. The BiOI photocatalyst exhibited the greatest photocatalytic activity at the natural $\mathrm{pH}$ (Figure 6a). In the basic solution of $\mathrm{pH}=10$, however, a negative charge on the $\mathrm{BiOI}$ photocatalyst surface and on the RhB dye molecules was seen to occur. Therefore, the repulsion between the photocatalyst and $\mathrm{RhB}$ dye lowers the $\mathrm{RhB}$ dye adsorption on the photocatalyst surface, which lowers the resultant photocatalytic performance. In contrast, by using an acidic solution of $\mathrm{pH}=5$, a decrease in photocatalytic efficiency was detected. This is attributed to the dissolution of the BiOI photocatalyst in acidic conditions $[3,8]$. Thus, further work was carried out by controlling the initial solution $\mathrm{pH}$ at the natural $\mathrm{pH}$ of RhB dye.

The effect of the photocatalyst content $(25-75 \mathrm{mg})$ on the photoactivity of the photocatalyst was also investigated (Figure 6b). Increasing the photocatalyst content resulted in an enhancement of the photocatalytic efficiency. This may be attributed to the increase in the number of RhB molecules adsorbed on the photocatalyst surface together with increments in the photocatalyst particle density per unit area of light illumination $[3,8,24,28]$. Incorporation of photocatalyst content from $25 \mathrm{mg}$ to $50 \mathrm{mg}$ caused a remarkable improvement in the photocatalytic activity. It should be noted that the addition of the photocatalyst content to up to $75 \mathrm{mg}$ did not strongly increase the performance of the photocatalyst. Therefore, the photocatalyst of $50 \mathrm{mg}$ was selected for further investigation.

The influence of the initial concentration on performance was also elucidated. An increase in RhB dye concentration resulted in a decrease in photoactivity (Figure 6c). Upon increasing the RhB concentration, most of the light could be absorbed by the RhB dye instead of the BiOI photocatalyst. Thus, a decrease in photo flux entering the surface of the photocatalyst would occur. This would cause a decrease in the performance of the photocatalyst [3,8]. It can be clearly seen that the greatest RhB concentration of $20 \mathrm{ppm}$ provided the lowest photocatalytic performance. 


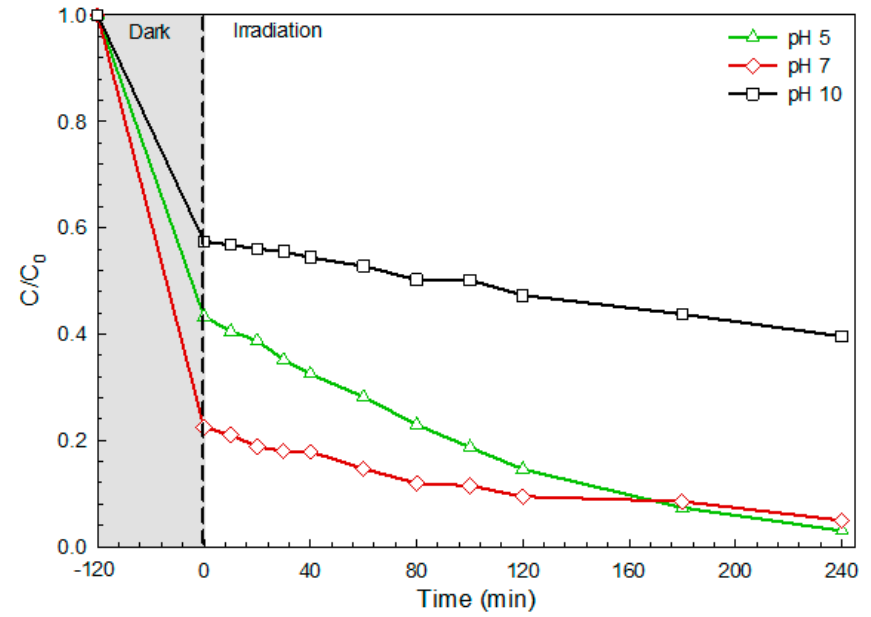

(a)

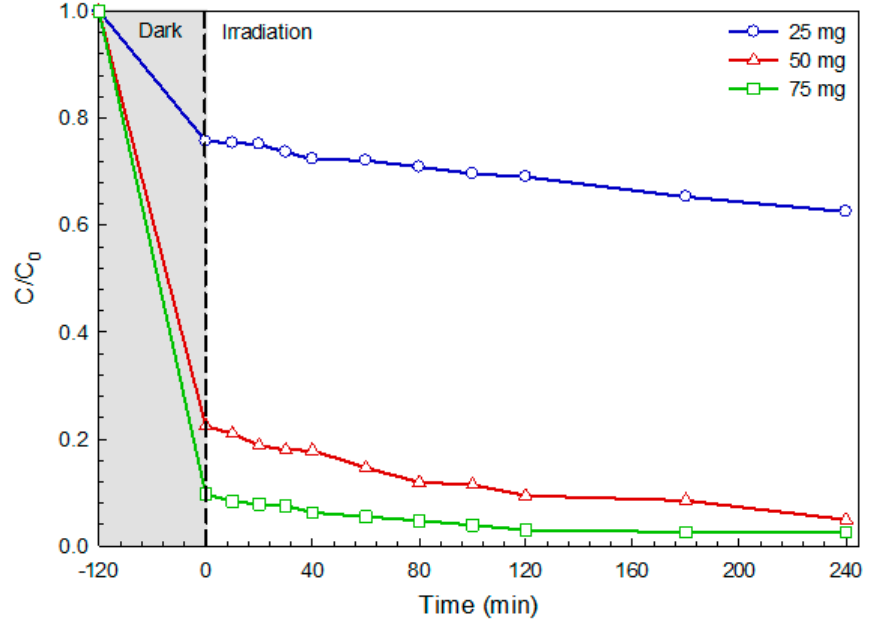

(b)

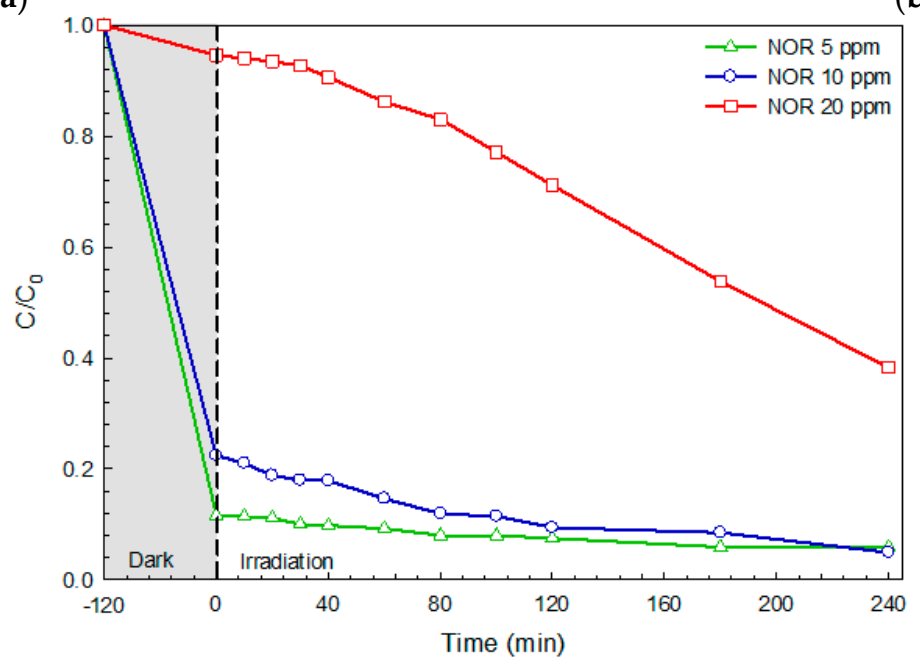

(c)

Figure 6. The effect of initial solution $\mathrm{pH}(\mathbf{a})$, photocatalyst content (b), and dye concentration (c) on the efficiency of the degradation of RhB dye.

\subsubsection{Photodegradation Mechanism and Cycling Ability}

The photodegradation mechanism of the pollutant was proposed by determining the results obtained from the trapping experiment $[3,8,24,28]$. The effect of some quenchers on $\mathrm{RhB}$ dye removal was examined after the incorporation of 2-propanol, $\mathrm{NaN}_{3}$, EDTA-2Na, and $\mathrm{K}_{2} \mathrm{Cr}_{2} \mathrm{O}_{7}$ as a quencher of ${ }^{\bullet} \mathrm{OH},{ }^{\bullet} \mathrm{O}_{2}^{-}, h^{+}$, and $e^{-}$, respectively. In the presence of either $\mathrm{NaN}_{3}$ or 2-propanol, the $\mathrm{C} / \mathrm{C}_{0}$ was close to that obtained from the no-scavenger process (Figure 7a). A corresponding efficiency of higher than $80 \%$ was observed after the incorporation of either $\mathrm{NaN}_{3}$ or 2-propanol. On the contrary, a dramatic lowering of the performance to nearly $40 \%$ was detected after the incorporation of either $\mathrm{K}_{2} \mathrm{Cr}_{2} \mathrm{O}_{7}$ or EDTA-2Na. The results indicate the vital role of both photogenerated electrons and holes in the removal of $\mathrm{RhB}$ dye in the solution.

Confirmation of the generated hydroxyl radicals $\left({ }^{\bullet} \mathrm{OH}\right)$, after photo irradiation, was performed by studying the terephthalic acid (TA) trapping experiment $[3,28]$. In principle, the reaction of TA and hydroxyl radicals should result in the formation of a highly fluorescent 2-hydroxyterephthalic acid (HTA). The addition of PL intensity at $425 \mathrm{~nm}$ after increasing the light illumination time was observed (Figure $7 \mathrm{~b}$ ), suggesting the creation of HTA. The result indicates that radicals play a role in the removal of pollutants. 


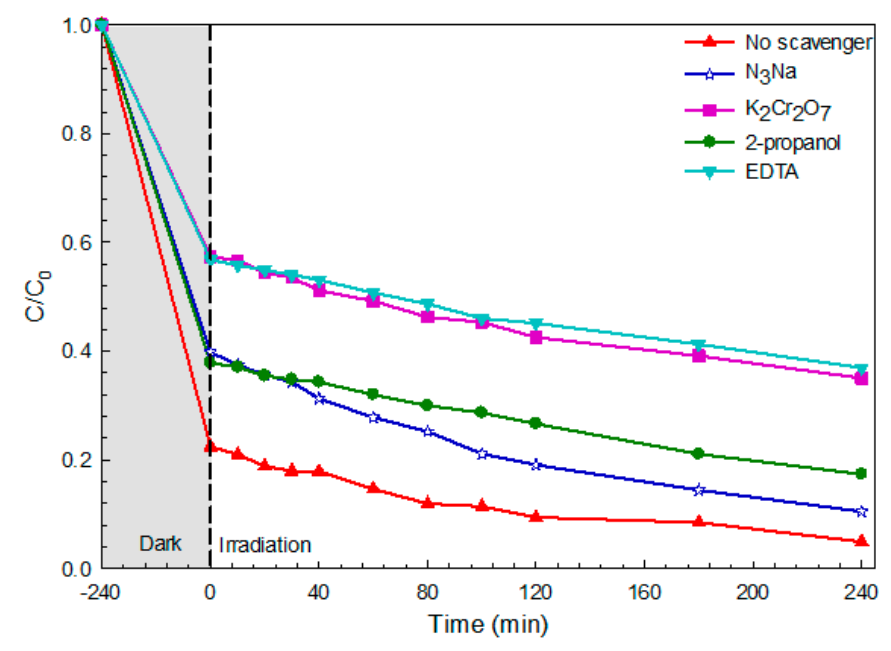

(a)

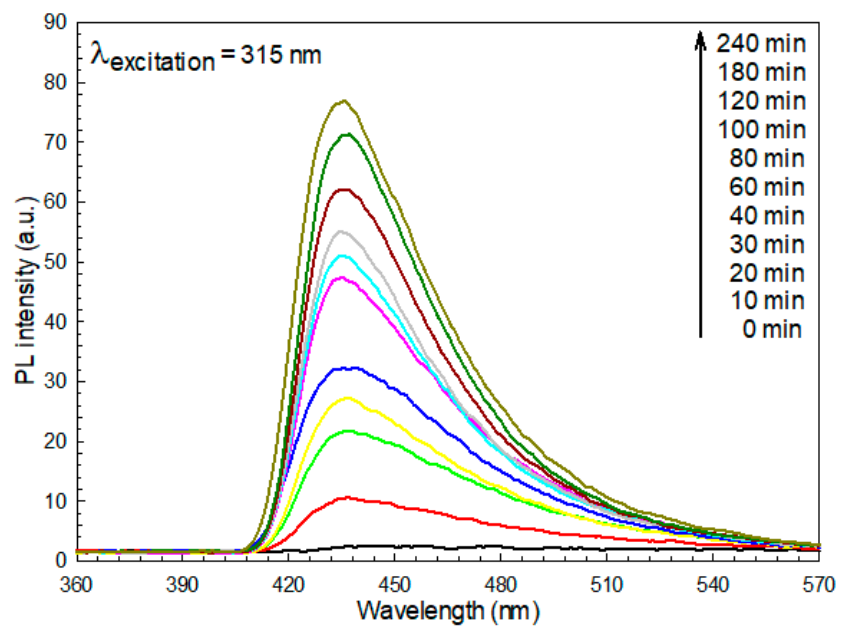

(b)

Figure 7. A decrease in $\mathrm{C} / \mathrm{C}_{0}$ with time due to photodegradation of $\mathrm{RhB}$ dye after addition of various scavengers (a), and hydroxyl radical trapping PL spectra of the prepared BiOI photocatalyst after photo irradiation (b).

After photo irradiation of the semiconducting photocatalyst, in principle, the generation of the electron and hole was achieved in the conduction band (CB) and the valence band (VB), respectively. After that, the reactive species were generated. The level of the $C B$ and the VB potentials of the BiOI photocatalyst can be evaluated by using the Mulliken electronegativity theory $[3,28]$, as shown below.

$$
\begin{gathered}
E_{\mathrm{VB}}=\chi-E_{\mathrm{C}}+0.5 E_{\mathrm{g}} \\
E_{\mathrm{CB}}=E_{\mathrm{VB}}-E_{\mathrm{g}}
\end{gathered}
$$

where $E_{\mathrm{VB}}$ and $E_{\mathrm{CB}}$ are the $\mathrm{VB}$ potential and $\mathrm{CB}$ potential, respectively. $E_{\mathrm{C}}$ and $\chi$ represents the standard hydrogen electrode potential $(\approx 4.5 \mathrm{eV})$ and the absolute value of the electronegativity $(6.65 \mathrm{eV})$ of the prepared $\mathrm{BiOI}$, respectively [18]. The corresponding VB and $\mathrm{CB}$ level of 2.78 and $0.63 \mathrm{eV}$, respectively, can be obtained from the prepared BiOI photocatalyst. The degradation mechanism of the pollutants can be proposed as follows.

$$
\begin{gathered}
\mathrm{BiOI}+h v \rightarrow \mathrm{BiOI}+e^{-}+h^{+} \\
e^{-}+\mathrm{O}_{2} \rightarrow{ }^{\bullet} \mathrm{O}_{2}{ }^{-} \\
\mathrm{O}_{2}{ }^{-}+2 \mathrm{H}_{2} \mathrm{O}+e^{-} \rightarrow 2^{\bullet} \mathrm{OH}+2 \mathrm{OH}^{-} \\
h^{+}+\mathrm{OH}^{-} \rightarrow \bullet \cdot \mathrm{OH} \\
\cdot \mathrm{OH}+\text { pollutants } \rightarrow \text { products } \\
h^{+}+\text {pollutants } \rightarrow \text { products }
\end{gathered}
$$

The detail of the photocatalytic degradation mechanism of the organic pollutants by the prepared BiOI photocatalyst can be summarized as shown in Figure 8. The stability of the sample is a crucial factor concerning its real-scale utilization. The cycling ability of the BiOI after the removal of organic pollutants was elucidated [3,8,24,28]. After five times uses, the $\mathrm{BiOI}$ photocatalyst retains its promising performance toward degradation of RhB and NOR (Figure 9a,b). The structural stability of the BiOI photocatalyst was also investigated. The XRD patterns (Figure 9c) of the photocatalyst from both before and after pollutant degradation were similar, implying the structural stability of the sample. Moreover, the morphology of the BiOI photocatalyst after the photodegradation study (Figure 9d) was identical to that of the fresh photocatalyst (Figure 2a). This also strongly supports the morphological stability of the BiOI photocatalyst [3,24,28-32]. 


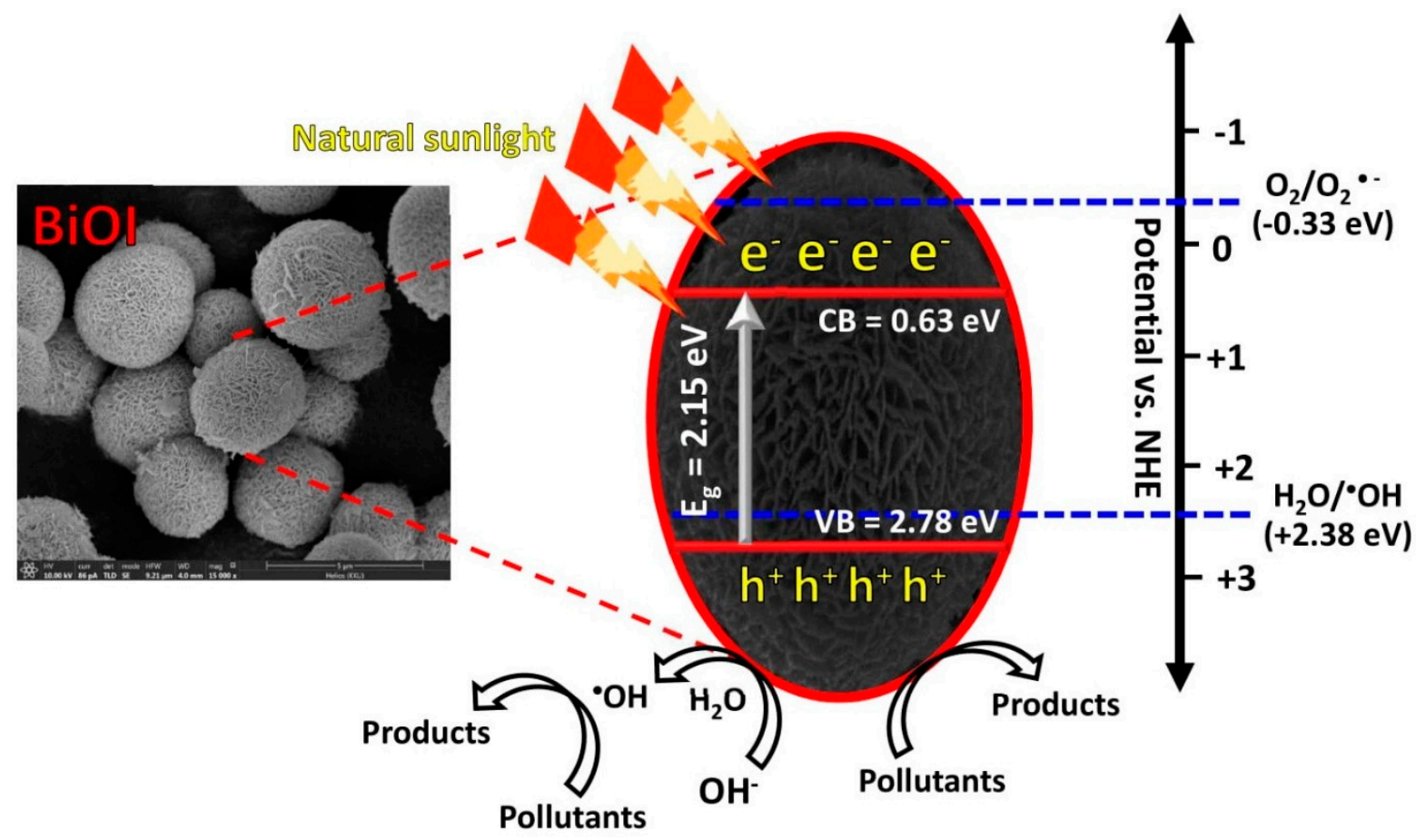

Figure 8. A possible photodegradation mechanism of organic pollutants over BiOI photocatalyst after photo illumination.

(a)

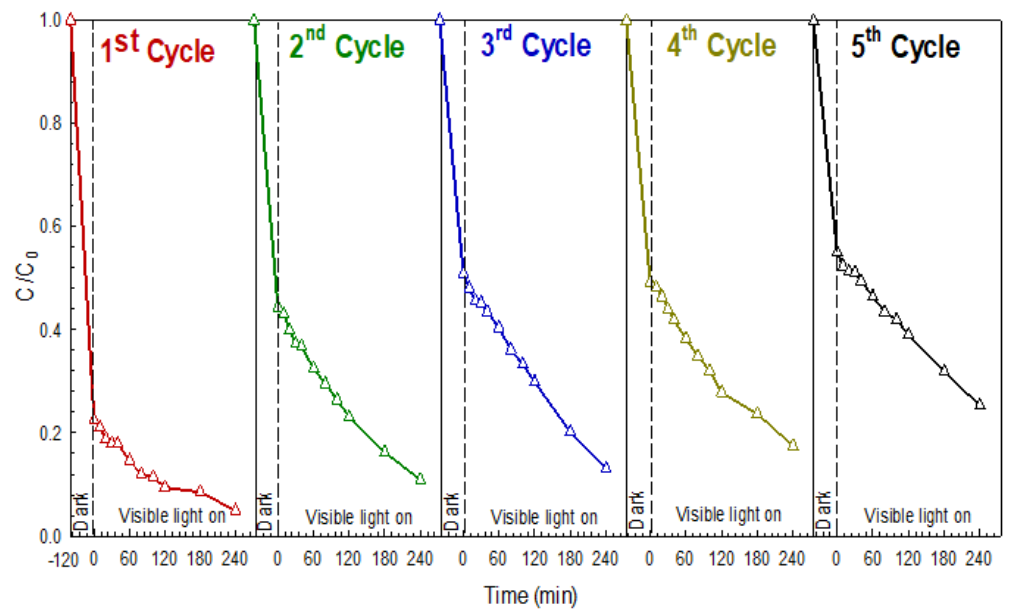

(b)

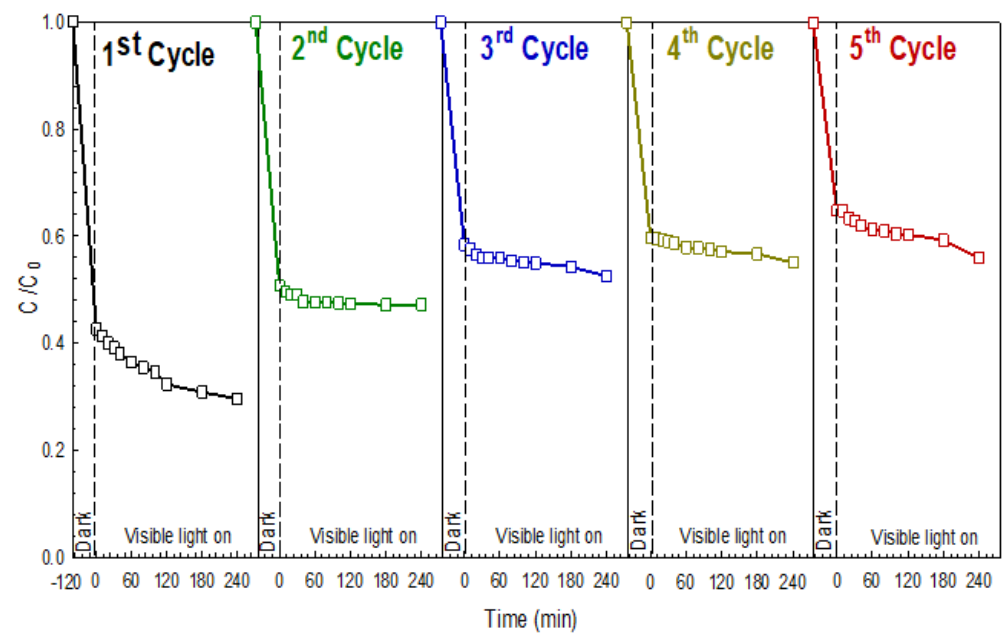

Figure 9. Cont. 
(c)

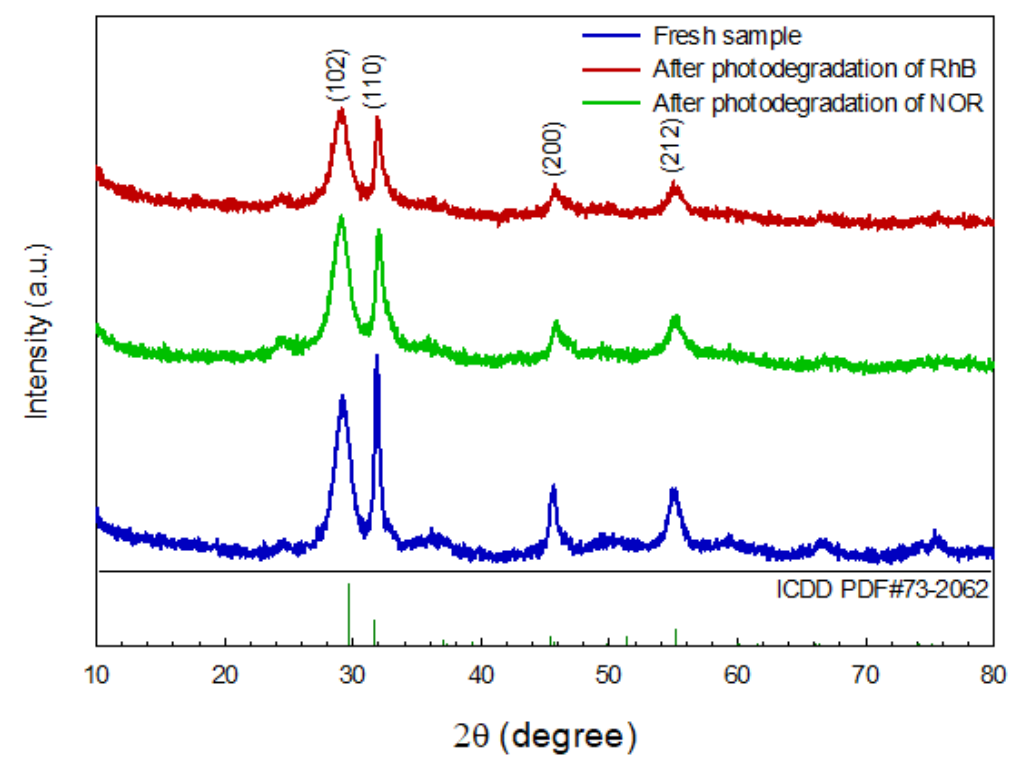

(d)

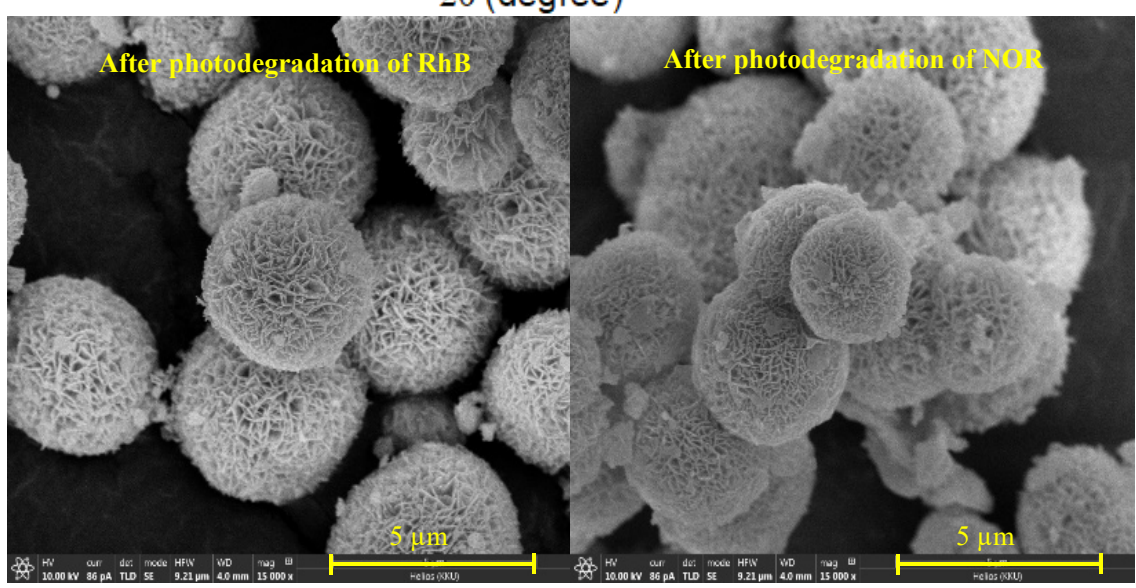

Figure 9. Reusability of the photocatalyst in the degradation of RhB dye (a), and NOR antibiotic (b), XRD patterns (c), and SEM micrographs (d) after the photodegradation of RhB dye and NOR antibiotic.

The photoactivity of the photocatalysts in the photodegradation of various organic pollutants has been investigated [3,24,28,33-37]. As seen in Table S1 (Supplementary Materials), various photocatalysts including binary and ternary composites showed an approximately 70-97\% removal of NOR antibiotics. In addition, the degradation of RhB dye in the range of $92-100 \%$ can be obtained from numerous photocatalysts. Herein, the $\mathrm{BiOI}$ photocatalyst has been utilized for the removal of both dye and antibiotic pollutants. The solvothermally grown $\mathrm{BiOI}$ provided visible-light-responsive photoactivity of $71 \%$ and 95\% toward the degradation of RhB and NOR, respectively. Interestingly, the prepared $\mathrm{BiOI}$ photocatalyst also provided a promising sunlight-active efficiency of $100 \%$ without the addition of a capping agent or the creation of composites. The present work demonstrates the enhanced photocatalytic performance of the prepared $\mathrm{BiOI}$ photocatalyst for the removal of pollutants by using abundant solar energy.

\section{Conclusions}

A solvothermally grown tetragonal $\mathrm{BiOI}$ photocatalyst with a band gap of $2.15 \mathrm{eV}$ was prepared using a green method. The catalyst provides a high sunlight-active photoactivity of $100 \%$ in the photodegradation of RhB dye due to its great charge carrier separation efficiency at the interface. The degradation reaction correlates well with the first-order reaction. The photogenerated hole and electron play major roles in the removal of the pollutant. The prepared BiOI catalyst remains stable and still exhibits promising efficiency 
after five runs, indicating its enhanced efficiency for the detoxification of pollutants in wastewater. This is due to the very high surface area (about $118 \mathrm{~m}^{2} \mathrm{~g}^{-1}$ ) of the prepared $\mathrm{BiOI}$, which can also act as an excellent adsorbent. The contribution of both adsorption and photocatalysis is a major factor concerning very high pollutant-removal efficiency. Enhanced performance under natural solar light supports the practical use of the BiOI photocatalyst for the removal of toxic organic pollutants in aqueous solutions by the utilization of abundant solar energy.

Supplementary Materials: The following are available online, Table S1: Comparison of pollutant degradation by using various photocatalysts.

Author Contributions: Conceptualization, S.N.; methodology, T.N.; investigation, T.S., T.C.; writingoriginal first draft, T.N.; writing - review and editing, S.N.; supervision, S.N.; funding acquisition, S.N. All authors have read and agreed to the published version of the manuscript.

Funding: We would like to acknowledge the financial support from the Materials Chemistry Research Center and PERCH-CIC. S.N. would like to acknowledge the fund supported by Research and Graduate Studies, Khon Kaen University (Research Program, grant number RP64-2-Canabis/001), fiscal year 2021.

Informed Consent Statement: Not applicable.

Data Availability Statement: Not applicable.

Conflicts of Interest: The authors declare no conflict of interest.

Sample Availability: Samples of the compounds are not available from the authors.

\section{References}

1. He, Q.; Xin, J.; Mao, L.; Cai, X.; Ding, B.; Zhang, L.; Zhang, J.; Zheng, S.; Yang, Y. Insitu growth of BiVO $4 / \mathrm{HoVO}_{4}$ heterojunction with $\mathrm{OO}$ bond connection for enhanced photodegradation activity. Mater. Lett. 2021, 284, 128952-128956. [CrossRef]

2. Xu, J.; Bian, Z.; Xin, X.; Chen, A.; Wang, H. Size dependence of nanosheet $\mathrm{BiVO}_{4}$ with oxygen vacancies and exposed $\{001\}$ facets on the photodegradation of oxytetracycline. Chem. Eng. J. 2018, 337, 684-696. [CrossRef]

3. Chankhanittha, T.; Nanan, S. Visible-light-driven photocatalytic degradation of ofloxacin (OFL) antibiotic and Rhodamine B (RhB) dye by solvothermally grown $\mathrm{ZnO} / \mathrm{Bi}_{2} \mathrm{MoO}_{6}$ heterojunction. J. Colloid Interface Sci. 2021, 582, 412-427. [CrossRef] [PubMed]

4. Ma, Z.; Huang, X.; Xu, N.; Li, J.; Zhou, C.; Deng, L.; He, Y. An effective strategy for boosting photoinduced charge separation of $\mathrm{Ag}_{3} \mathrm{PO}_{4}$ by $\mathrm{BiVO}_{4}$ with enhanced visible light photodegradation efficiency for levofloxacin and methylene blue. Spectrochim. Acta Part A Mol. Biomol. Spectrosc. 2020, 229, 117986-117993. [CrossRef]

5. Qin, C.; Li, H.; Zhong, J.; Li, J.; Huang, S.; Ma, L. Preparation of cypress leave-like $\mathrm{Ag}_{2} \mathrm{WO}_{4} / \mathrm{BiVO}_{4}$ heterojunctions with remarkably enhanced photocatalytic activity. Mater. Lett. 2021, 283, 128793-128796. [CrossRef]

6. Senasu, T.; Nanan, S. Photocatalytic performance of CdS nanomaterials for photodegradation of organic azo dyes under artificial visible light and natural solar light irradiation. J. Mater. Sci. Mater. Electron. 2017, 28, 17421-17441. [CrossRef]

7. Senasu, T.; Hemavibool, K.; Nanan, S. Hydrothermally grown CdS nanoparticles for photodegradation of anionic azo dyes under UV-visible light irradiation. RSC Adv. 2018, 8, 22592-22605. [CrossRef]

8. Kakarndee, S.; Nanan, S. SDS capped and PVA capped ZnO nanostructures with high photocatalytic performance toward photodegradation of reactive red (RR141) azo dye. J. Environ. Chem. Eng. 2018, 6, 74-94. [CrossRef]

9. Chankhanittha, T.; Watcharakitti, J.; Nanan, S. PVP-assisted synthesis of rod-like ZnO photocatalyst for photodegradation of reactive red (RR141) and Congo red (CR) azo dyes. J. Mater. Sci. Mater. Electron. 2019, 30, 17804-17819. [CrossRef]

10. Li, W.; Ding, X.; Wu, H.; Yang, H. In-situ hydrothermal synthesis of $\mathrm{TiO}_{2} / \mathrm{Bi}_{2} \mathrm{WO}_{6}$ heterojunction with enhanced photocatalytic activity. Mater. Lett. 2018, 227, 272-275. [CrossRef]

11. Zhang, J.; Huang, L.; Yang, L.; Lu, Z.; Wang, X.; Xu, G.; Zhang, E.; Wang, H.; Kong, Z.; Xi, J.; et al. Controllable synthesis of $\mathrm{Bi}_{2} \mathrm{WO}_{6}(001) / \mathrm{TiO}_{2}(001)$ heterostructure with enhanced photocatalytic activity. Alloys Compd. 2016, 676, 37-45. [CrossRef]

12. Chankhanittha, T.; Somaudon, V.; Watcharakitti, J.; Nanan, S. Solar light-driven photocatalyst based on bismuth molybdate $\left(\mathrm{Bi}_{4} \mathrm{MoO}_{9}\right)$ for detoxification of anionic azo dyes in wastewater. J. Mater. Sci. Mater. Electron. 2021, 32, 1977-1991. [CrossRef]

13. Senasu, T.; Chankhanittha, T.; Hemavibool, K.; Nanan, S. Visible-light-responsive photocatalyst based on ZnO/CdS nanocomposite for photodegradation of reactive red azo dye and ofloxacin antibiotic. Mater. Sci. Semicond. Process. 2020, $123,105558$. [CrossRef]

14. Hassani, A.; Faraji, M.; Eghbali, P. Facile fabrication of $m p g-\mathrm{C}_{3} \mathrm{~N}_{4} / \mathrm{Ag} / \mathrm{ZnO}$ nanowires $/ \mathrm{Zn}$ photocatalyst plates for photodegradation of dye pollutant. J. Photochem. Photobiol. A Chem. 2020, 400, 112665. [CrossRef]

15. Arumugam, M.; Choi, M.Y. Recent progress on bismuth oxyiodide (BiOI) photocatalyst for environmental remediation. J. Ind. Eng. Chem. 2020, 81, 237-268. [CrossRef] 
16. Duo, F.; Fan, C.; Wang, Y.; Cao, Y.; Zhang, X. One-pot hydrothermal synthesis of a novel $\mathrm{BiPO}_{4} / \mathrm{BiOBr}$ composite with enhanced visible light photocatalytic activities. Mater. Sci. Semicond. Process. 2015, 38, 157-164. [CrossRef]

17. Huang, X.; Guo, Q.; Yan, B.; Liu, H.; Chen, K.; Wei, S.; Wu, Y.; Wang, L. Study on photocatalytic degradation of phenol by $\mathrm{BiOI} / \mathrm{Bi}_{2} \mathrm{WO}_{6}$ layered heterojunction synthesized by hydrothermal method. J. Mol. Liq. 2021, 322, 114965. [CrossRef]

18. Wang, J.; Huang, Y.; Guo, J.; Zhang, J.; Wei, X.; Ma, F. Optoelectronic response and interfacial properties of BiOI/BiOX (X=F, Cl, $\mathrm{Br}$ ) heterostructures based on DFT investigation. J. Solid State Chem. 2020, 284, 121181. [CrossRef]

19. Liu, Z.S.; Ran, H.S.; Wu, B.T.; Feng, P.Z.; Zhu, Y.B. Synthesis and characterization of BiOI/BiOBr heterostructure films with enhanced visible light photocatalytic activity, Colloids Surfaces A Physicochem. Eng. Asp. 2014, 452, 109-114. [CrossRef]

20. Jiang, W.; Li, Z.; Liu, C.; Wang, D.; Yan, G.; Liu, B.; Che, G. Enhanced visible-light-induced photocatalytic degradation of tetracycline using BiOI/MIL-125(Ti) composite photocatalyst. J. Alloys Compd. 2021, 854, 157166. [CrossRef]

21. Liu, J.; Qiu, L.; Chang, M.J.; Yuan, B.; Sun, M.; Fan, S.M.; Cui, W.N.; Hui, Q.; Ni, F.R.; Li, M.Y.; et al. Fabrication of novel fibrous $\mathrm{BiVO}_{4} / \mathrm{CdS}$ heterostructures by electrospinning method for efficient visible light photodegradation. Mater. Chem. Phys. 2020, 247, 122858. [CrossRef]

22. Chankhanittha, T.; Somaudon, V.; Watcharakitti, J.; Piyavarakorn, V.; Nanan, S. Performance of solvothermally grown $\mathrm{Bi}_{2} \mathrm{MoO}_{6}$ photocatalyst toward degradation of organic azo dyes and fluoroquinolone antibiotics. Mater. Lett. 2020, 258, 126764-126769. [CrossRef]

23. Rathi, V.; Panneerselvam, A.; Sathiyapriya, R. A novel hydrothermal induced $\mathrm{BiVO}_{4} / \mathrm{g}-\mathrm{C}_{3} \mathrm{~N}_{4}$ heterojunctions visible-light photocatalyst for effective elimination of aqueous organic pollutants. Vacuum 2020, 180, 109458-109467. [CrossRef]

24. Senasu, T.; Narenuch, T.; Wannakam, K.; Chankhanittha, T.; Nanan, S. Solvothermally grown BiOCl catalyst for photodegradation of cationic dye and fluoroquinolone-based antibiotics. J. Mater. Sci. Mater. Elect. 2020, 31, 9685-9694. [CrossRef]

25. Tang, W.; Zhang, Y.; Guo, H.; Liu, Y. Heterogeneous activation of peroxymonosulfate for bisphenol AF degradation with $\mathrm{BiOI}_{0.5} \mathrm{Cl}_{0.5}$. RSC Adv. 2019, 9, 14060-14071. [CrossRef]

26. Li, J.; Zhou, Q.; Yang, F.; Wu, L.; Li, W.; Ren, R.; Lv, Y. Uniform flower-like BiOBr/BiOI prepared by a new method: Visible-light photocatalytic degradation, influencing factors and degradation mechanism. New J. Chem. 2019, 43, 14829-14840. [CrossRef]

27. Li, S.; Lu, H.; Zhu, G.; Hojamberdiev, M.; Gao, J.; Wei, X.; Liu, P. A recyclable and stable BiOI/agarose hybrid gel photocatalyst for photodegradation of Rhodamine B. J. Mater. Sci. Mater. Elect. 2018, 29, 16454-16459. [CrossRef]

28. Narenuch, T.; Senasu, T.; Chankhanittha, T.; Nanan, S. Solvothermal synthesis of CTAB capped and SDS capped BiOCl photocatalysts for degradation of rhodamine B (RhB) dye and fluoroquinolone antibiotics. J. Solid State Chem. 2020, $294,121824$. [CrossRef]

29. Baral, B.; Parida, K. $\{040 / 110\}$ Facet Isotype Heterojunctions with Monoclinic Scheelite BiVO 4 . Inorg. Chem. 2020, 59, 10328-10342. [CrossRef]

30. Dang, M.; Tan, G.; Wang, M.; Zhang, B.; Wang, Y.; Lv, L.; Ren, H.; Xia, A. Preparation and photocatalytic enhancement mechanism of $\mathrm{g}-\mathrm{C}_{3} \mathrm{~N}_{4} /(110)$ facet $\mathrm{BiVO}_{4}$ heterojunction induced by electrostatic field. Mater. Lett. 2021, 285, 129131-129134. [CrossRef]

31. Nguyen, T.D.; Hong, S.S. Facile solvothermal synthesis of monoclinic-tetragonal heterostructured $\mathrm{BiVO}_{4}$ for photodegradation of rhodamine B. Catal. Commun. 2020, 136, 105920-105924. [CrossRef]

32. Ye, S.; Zhoua, X.; Xu, Y.; Lai, W.; Yan, K.; Huang, L.; Ling, J.; Zheng, L. Photocatalytic performance of multi-walled carbon nanotube $/ \mathrm{BiVO}_{4}$ synthesized by electro-spinning process and its degradation mechanisms on oxytetracycline. Chem. Eng. J. 2019, 373, 880-890. [CrossRef]

33. Wang, Y.; Yang, Q.; Wang, X.; Yang, J.; Dai, Y.; He, Y.; Chen, W.; Zhang, W. Photocatalytic degradation of rhodamin B and diclofenac sodium on hollow hierarchical microspheres of BiOBr modified with sepiolite and polyvinyl pyrrolidone (PVP). Mater. Sci. Eng. B Solid-State Mater. Adv. Technol. 2019, 244, 12-22. [CrossRef]

34. Zhang, Y.; Zhou, J.; Cai, W.; Zhou, J.; Li, Z. Enhanced photocatalytic performance and degradation pathway of Rhodamine B over hierarchical double-shelled zinc nickel oxide hollow sphere heterojunction. Appl. Surf. Sci. 2018, 430, 549-560. [CrossRef]

35. Wermuth, T.B.; Arcaro, S.; Venturini, J.; Ribeiro, T.M.H.; de Assis Lawisch Rodriguez, A.; Machado, E.L.; de Oliveira, T.F.; de Oliveira, S.E.F.; Baibich, M.N.; Bergmann, C.P. Microwave-synthesized $\mathrm{KNbO}_{3}$ perovskites: Photocatalytic pathway on the degradation of rhodamine B. Ceram. Int. 2019, 45, 24137-24145. [CrossRef]

36. Roy, J.S.; Dugas, G.; Morency, S.; Messaddeq, Y. Rapid degradation of Rhodamine B using enhanced photocatalytic activity of $\mathrm{MoS}_{2}$ nanoflowers under concentrated sunlight irradiation. Phys. E Low-Dimens. Syst. Nanostruct. 2020, 120, 114114. [CrossRef]

37. Yue, W.; Wang, Z.; Gong, J.; Wang, Z.; Dong, Y. Synthesis of tetrapod CdS by one-pot Solvothermal Method for Photodegradation to rhodamine B. Mater. Sci. Semicond. Process. 2021, 125, 105671. [CrossRef] 